\title{
TRABALHO X DOENTE MENTAL: PERCEPÇÃO DA FAMILIA
}

\author{
WORK X MENTAL ILL: FAMILY'S PERCEPTIONS \\ TRABAJO X ENFERMO MENTAL: PERCEPCIÓN DE LA FAMILIA.
}

Ana Ruth Macêdo Monteiro'

Maria Grasiela Teixeira Barroso ${ }^{2}$

\begin{abstract}
RESUMO: A relação familia $\mathrm{x}$ doente mental, muito mais presente na reforma psiquiátrica, constitui a possibilidade de criar novos caminhos em busca de compreender como a familia percebe a relaçāo trabalho $x$ doente mental. É considerado, nesta pesquisa, como elemento fundamental o discurso dos componentes da familia do doente, em razăo da sua experiência vivida. $\mathrm{Na}$ relaçāo doente mental e trabalho, a familia descreve várias dificuldades, onde a ociosidade está presente, revelando a incapacidade do seu componente para o trabalho, ou indigitando-Ihe uma ocupação diferenciada adaptado a sua condição de doente, não percebendo o possivel estado depressivo que possa estar vivenciando, como manifestação de sua patologia.
\end{abstract}

PALAVRAS-CHAVE: trabalho, doente mental, familia

\section{INTRODUÇĀO:}

A psiquiatria vem, ao longo dos anos, passando várias transformaçöes que muito tem influenciado na sua prática profissional. Essas modificações provocaram algumas reflexões e serviram de base para a atual Reforma Psiquiátrica que inspirada no modelo italiano, propōe novo paradigma para presidir as atençōes à saúde mental.

Com os estudos na psiquiatria, várias propostas de reforma foram surgindo, algumas com uma visão diferenciada de tratamento da doença mental, mas o modelo hospitalocêntrico era o que permanecia. Nesse molde, o doente mental era internado por um longo periodo, recebendo um tratamento não personalizado, não possuindo identidade nem havendo eqüidade nessa assistência que lhe era prestada.

Vivenciamos hoje, um Movimento de Reforma Psiquiátrica, que, há alguns anos, vem propondo nova filosofia no tratamento utilizado em psiquiatria, contendo uma proposta de "invenção de saúde" e de "reproduçăo social do paciente", avessa, portanto, à centralização no processo de cura, que resultou insuficiente e ineficaz até hoje. Dentro dessa visão, o problema da psiquiatria não é mais a cura, a vida produtiva, mas a produçăo de vida voltada para a sociabilidade, utilização dos "espaços coletivos" e de "convivência dispersa" (Rotelli,1990,p.30).

O projeto de Lei $n^{\circ} 3.657$, de 1989 , do Deputado Paulo Delgado, em sua justificação, afirma: " a desospitalizaçăo é um processo irreversivel, que vem demonstrando ser o manicômio plenamente substituivel por serviços alternativos mais humanos, menos

'Enfermeira, Doutoranda em Enfermagem/UFC. Professora Adjunta da Universidade Estadual do Ceará. Enfermeira do Hospital de Messejana/SUS.

${ }^{2}$ Enfermeira Livre Docente. Professora Titular da Universidade Federal do Ceará. 
estigmatizantes, menos violentos e mais terapêuticos " . O referido projeto dispōe sobre a extinção progressiva dos manicômios e sua substituição por outros recursos assistenciais e regulamenta a internação psiquiátrica compulsória.

No Ceará, a Lei n ${ }^{\circ} 12.151$, de 1993(CEARÁ,1993), proposta pelo Deputado Mário Mamede, estende a desospitalização ao Estado, citando no seu Art. $2^{\circ}$.

"A Secretaria Estadual de Saúde, as comissőes interinstitucionais, o conselho estadual, as comissões municipais, locais e as Secretarias Municipais de Saúde, estabelecerão a planificação necessária para a instalação e o funcionamento de recursos alternativos de atendimento, com leitos psiquiátricos em hospitais gerais, hospital-dia, hospital-noite, centro de atenção, centros de convivência, lares, pensōes protegidas, entre outros, bem como estabelecerão, conjuntamente, critérios para viabilizar o disposto no parágrafo único do artigo anterior, fixando a extinção progressiva dos leitos psiquiátricos" .

Nessa convivência com a familia em seu mundo-vida, o chamado louco, pelo preconceito social existente acerca da doença mental, tem a oportunidade de experienciar situações ainda não vivenciadas, quando se transmuda em sujeito, deixando de ser objeto da assistência prestada. A doença mental, de uma maneira generalizada, é entendida pela sociedade como uma doença incurável e que deve ser tratada em total reclusão a fim de evitar os perigos que os rotulados de desordenados mentais -os loucos- podem trazer para o meio social.

Conviver com o doente mental, sob essa visão, dificulta, com certeza, o desenvolvimento de sua auto-estima, já que o paciente se sente estigmatizado dentro do próprio ambiente familiar, oferecendo ensejo para a evolução do seu estado patológico, aumentando a frequeência das suas internaçōes.

Todas essas novas medidas de atendimento em saúde mental proporcionam ao usuário maior convivência familiar, o que não é possivel no sistema de hospital psiquiátrico, onde persiste a ideologia do isolamento do doente mental do seu meio, pois se o mesmo voltar a conviver com a sua "familia doente" , está sendo, no caso, devolvido "à fonte dos conflitos" . E essa idéia, se não trabalhada poderá "...induzir ingenuamente a uma reprivatizaçăo compulsória da loucura na familia ou simplesmente a uma processo de negligência social, em caso de sua ausência" (Vasconcelos, 1990,p.233).

Nessa prática de hospital-dia, a familia, apesar do preconceito social acerca da doença do seu familiar, tem participado das atividades propostas pelo serviço, entre as quais a reunião mensal com os técnicos responsáveis, recebendo o usuário em casa, incluindo-o na convivência familiar. Essa prática abre um espaço para a atuação da enfermagem.

A enfermagem tem o objetivo de cuidar do individuo como ser único, porém membro de uma familia e que interage com outros grupos sociais, vivendo em uma comunidade e em um determinado ambiente, dispondo-se a ir além, cuidando da familia (Elsen, 1994).

A familia é um núcleo de pessoas que convive em determinado lugar, durante um espaço de tempo mais ou menos longo e que se acham unidas ou não por laços de consangüinidade, que recebe influência da sociedade a que está relacionada, no que diz respeito à cultura e ideologia particulares, como também tem sobre ela influências especificas. (Loifer,1982, p. 22).

Uma forma aceitável de familia é aquele conjunto de pessoas que moram sob o mesmo teto, não importando o número de gerações. Conquanto seja essa afirmação falha, pois há exclusão de ascendentes e descendentes e colaterais que moram em um outro domicilio, mas exercem influência na dinâmica familiar, como também, há outras pessoas que nem moram na mesma casa, nem tem laços consangüineos, mas exercem também influência na mesma familia.(Bassit, 1992).

Consoante tais conceitos, percebe-se que a familia não é aquela formada necessariamente apenas pelos unidos por consangüinidade. São todos aqueles que estão próximos a ela e que exercem influência direta, negativa ou positiva sobre os seus membros. 
Com isso, entende-se que o doente mental terá uma gama de pessoas com quem se relacionar nesse novo processo de atendimento psiquiátrico, tendo que buscar adaptação junto a eles para superarem juntos os obstáculos que surgirăo.

Várias outras situações de adaptação, a familia do doente mental já vivenciou, experienciando bem o peso das pressōes psicológicas desenvolvidas pelas interaçōes familiares, como no caso do regresso do seu familiar que esteve hospitalizado. E nos casos em que a familia mostra-se flexivel, propiciando uma comunicação mais direta, a adaptação será facilitada. Tal situação não ocorre quando a familia está desequilibrada e desgastada em seus esforços para controlar os conflitos internos que são conseqũentes de uma crise mal elaborada.(Sordi, 1980).

Uma maior convivência familiar é conseqüente ao processo de ir-e-vir de um ser doente mental. Essa interação deve, pois, ser trabalhada, porquanto estando a familia em estado de desequilibrio e desgaste, a dinâmica familiar, decerto, estará alterada, sendo fonte de conflitos para os envolvidos.

Quando aparece um membro da familia com distúrbio mental, os outros elementos definem-se como sadios, colocando-se em posição oposta ao integrante doente, considerando o seu código de valores como absoluto e natural, sendo o ponto de partida dessa atitude o meio social que influencia na definição de quem é doente mental, e quem precisa de ajuda de um profissional. (Berenstein, 1988)

Com essa visão de doença mental e esse comportamento totalmente discriminatório, a familia nāo está preparada para conviver com o seu familiar doente, como sujeito participante do tratamento que lhe está sendo prestado, não apresentando condições de junto a ele construir possibilidades de uma vida com maior qualidade. Na verdade, historicamente a familia vem sendo para nåo conviver com o seu familiar doente mental, uma vez que até hoje é predominante o hospital psiquiátrico e suas longas internaçōes como opção quase exclusiva para o tratamento do doente mental.

As familias desenvolvem um papel representativo nas tarefas universais, e estando suficientemente sadias, elas ajudam os seus membros a superar individual e conjuntamente a angústia e o luto, não se livrando dessas duas dimensões, mas trabalhando cada uma delas como forma de superá-la. (Racamier, 1991)

Por ter esse papel representativo, a familia participa do momento em que surge a doença mental do seu familiar, bem como do seu desenvolvimento. Envolve-se nesse processo como sujeito e não vitima, de modo que necessita da equipe multiprofissional de saúde para facilitar não somente a sua interação com o doente mental, como também ensejar a integração deste à sociedade.É de grande a ocorrência de atendimento a pacientes psicóticos que são interrompidos ou mal sucedidos devido à atuação de seus familiares. Sabemos, também, que é alto o número de pacientes 'curados' que voltam ao hospital após convivio com suas familias... O paciente torna-se o porta-voz do inconsciente familiar, rompe a ilusão do mito fusional, introduz as diferenças: sexuais e geracionais.(Vilhena,1991, p.158-9).

A familia precisa ser tratada juntamente como o seu ser doente, para que o relacionamento entre ambos possa ser vivenciado harmonicamente, numa busca incessante rumo a uma melhor qualidade de vida, que está intrinsecamente ligada à questão social, pois esta é uma das causas que precipita a doença mental.

A cidadania é um direito inerente a qualquer pessoa, e deve ser conquistado a cada dia, em qualquer situação, onde haja a participação da comunidade, inclusive no que se refere à saúde mental, partindo dai as decisões e o controle de qualquer medida de segurança, pois essa conquista só poderá ser efetivada a partir do poder local.(Pitta,1992).

Esse direito de cidadania é ainda muito restrito no campo de saúde mental, em que a 
doença, como mencionado, é objeto de um preconceito social, partindo, muitas vezes, da própria familia que muito contribui para a reclusão do portador de tal distúrbio, isolando-o totalmente do gozo da sua familiaridade e do convivio em sociedade de uma maneira geral.

A familia retrata toda uma crise social, precisando ser trabalhada para superar com autenticidade essa gama de conflitos que vivencia na sua existência, como grupo primário que exerce influência, de forma quase predominante, sobre os que a constitui.

Na sociedade, a familia não é totalmente passiva, posto que tem um papel bem ativo a refletir nas mudanças sociais, politicas econômicas e religiosas. Bem assim influenciada por esses aspectos, o que a faz viver em verdadeiro processo. Na psiquiatria, o grupo familial está vivenciando novas formas de interação junto ao seu doente, ocupando um papel primordial na terapêutica, que tem como base a inserção social. "A familia estaria vivendo em rude impasse. Perdeu seus antigos valores sem conseguir criar nada que pudesse substitui-los. A mobilidade sócio-cultural do universo citadino privou-a de seus vinculos tradicionais e, ao mesmo tempo, da possibilidade de estabelecer novos relacionamento sólidos. Sem auxilio, portanto, ela estaria perdida, sem cuidados especializados, não encontraria saida para os conflitos em que se debate. (Costa,1983).

É fácil observar que a estrutura familiar encontra-se abalada e sem referência quando precisa de ajuda. Em se falando de saúde mental, a familia tem sido o alvo de toda a proposta terapêutica atual, necessitando de apoio e orientação para se obter uma resposta adequada, pois ela proporciona ao ser doente mental toda uma possibilidade de estar-com, manifestando junto a ele o se ser-aí.

Essa ajuda à familia, em busca da saúde dos seus membros, é um grande desafio para a enfermagem: o de 'cuidar de quem cuida', ou seja ir ao encontro da familia, conhecendo como cuida, identificando suas dificuldades e suas forças, para melhor atuação profissional, atendendo às suas necessidades. (Elsen,1994).

Com esse grande desafio, a enfermagem psiquiátrica poderá trazer grandes contribuiçöes para o processo de reforma psiquiátrica, que conta com a familia como participe no tratamento do seu familiar, buscando a adaptação deste à sua nova experiência domiciliar, vivenciando cada um a sua subjetividade, numa relação de co-existência.

Essa relação familia $x$ doente mental, muito mais presente na reforma psiquiátrica que está sendo proposta e vivenciada, constitui para mim a possibilidade de criar novos caminhos em busca de compreender como a familia percebe a relação trabalho $x$ doente mental.

\section{TRAJETÓRIA METODOLÓGICA}

Utilizei como fundamentação teórica, para este caminhar investigativo, dentro da modalidade de pesquisa qualitativa, a Análise da Estrutura do Fenômeno Situado, também denominada Análise Fenomenológica, tomando por referência básica um trabalho de Martins ; Bicudo (1994). Esta modalidade de pesquisa é fundamentada na fenomenologia como sistema filosófico. É difundida nos Estados Unidos pelo professor Amadeo Giorgi e, no Brasil, pelo professor Joel Martins. (Garanhani,1993).

Nessa modalidade de pesquisa, utiliza-se, como recurso metodológico para a coleta, a entrevista, considerada o melhor medium através do qual se obtém informações relevantes sobre o mundo-vida dos sujeitos.

É considerado, nesta pesquisa, como elemento fundamental o discurso dos componentes da familia do doente, em razão da sua experiência vivida. É através desse discurso que o mundo-vida dessas pessoas se torna acessivel, na relação sujeito que vivencia e pesquisador que interroga.

Os relatos de experiências foram buscados junto às familias dos usuários do hospitaldia do Sistema Único de Saúde-SUS da cidade de Fortaleza, Estado do Ceará - Brasil. As 
familias entrevistadas foram aquelas que tinham um dos seus componentes como usuários freqüentando o hospital-dia de uma a três vezes por semana e que aceitaram participar como sujeitos desta pesquisa. Essa opção deveu-se ao fato de que nesses casos há maior convivência do usuário com a sua familia, vivenciando mais a dinâmica do ir-e-vir.

O recurso metodológico utilizado para coleta dos depoimentos foi a entrevista, pois permite que o sujeito descreva as situações por ele vivenciadas, relatando o seu mundo-vida, mantendo, dessa forma, uma relação com o entrevistador num diálogo que tem a finalidade de obter informaçöes úteis importantes para ambos, e consideradas básicas para a compreensão do mundo-vida do sujeito, de importância primordial para o conteúdo global deste estudo.

Após ter sido estabelecido um contato inicial com a familia apresentei-me, explicando, de forma clara, o meu interesse em ouvi-los contar a respeito das suas experiências com o ire-vir desde que a pessoa se encontrasse disposta a conversar. Solicitei o consentimento para que utilizasse o gravador, esclarecendo enfaticamente, que o anonimato seria preservado para a segurança do entrevistado, podendo ele tranquilamente relatar tudo o que quisesse sobre o assunto.

A concordância dos membros da familia para a entrevista, foi pedida particularmente a cada componente e, somente após o seu aceite, ela era realizada. Também o usuário era contactado, inicialmente, no sentido de se colocar quanto à concordância ou não de que a referida entrevista se realizasse, uma vez que poderia se sentir invadido na sua privacidade. Esse encontro social com a familia aconteceu, em sua maioria, sem a presença do usuário do hospital-dia, pois, acredita-se que dessa forma o relato pode ser feito sem restriçōes, ocorrendo no seu ambiente familiar, local principal onde ocorrem as relações interfamiliares.

Foram necessárias várias visitas a uma mesma familia, em decorrência do fato de nem sempre se encontrar todos da familia em casa no momento da primeira ou segunda entrevista. Todos os entrevistados foram cooperativos com a entrevista, permitindo o uso do gravador.

$\mathrm{Na}$ tentativa de compreender e conhecer a experiência vivenciada pelas familias dos usuários do hospital-dia foi utilizado uma questão norteadora: COMO VOCÊ PERCEBE A RELAÇÄO TRABALHO X DOENÇA MENTAL?

A partir desse questionamento, permitia-se que falassem à vontade e, em alguns momentos, sempre que necessário, foram feitas interrupçőes para se retomar a questão proposta e, caso o entrevistado não conseguisse se manter na linha da pauta, solicitava-se para que esclarecesse pontos de suas falas, utilizando-se das últimas palavras ou expressōes descritas pelos sujeitos da experiência. O término da entrevista se dava quando o sujeito da pesquisa, então entrevistado, não tinha mais nada a mencionar.

A coleta dos depoimentos era finalizada quando estes se apresentavam suficientes para responder ao que se investigava. Este momento foi determinado quando os discursos começaram a convergir, não mais trazendo nenhuma contribuição significativa para o desvelamento do fenômeno. Esse periodo correspondeu aos meses de junho a setembro de 1996 tendo sido a amostra formada por sete familias, totalizando 12 pessoas.

Como se disse noutra passagem, a análise dos discursos seguiu a orientação de Martins ; Bicudo (1994), que afirmam deve ser a interpretação das falas feitas à medida que os dados văo sendo coletados, compondo unidades de significados.

Para se chegar a essa análise da estrutura geral do fenômeno, foi feita, inicialmente, a análise individual da entrevista de per se, para partir do individual para o geral, através da análise nomotética. Aqui, a estrutura geral do fenômeno - a experiência da familia com o ir-e-vir de um de seus componentes ao (do) hospital-dia- resultou das convergências e divergências que se mostraram na análise individual. Foram observados todos os passos esposados no estudo de Martins ; Bicudo (1994). 


\section{A OCIOSIDADE PRESENTE E O TRABALHO DIFERENCIADO}

Um grande problema enfrentado pelo doente mental é a ociosidade, que o cerca desde o seu anterior tratamento em hospital psiquiátrico, e, agora, como participante do hospital-dia, pois, nos dias em que não o freqüenta, não tem atividade com que se ocupe.

Essa situação percebida pela familia e relatada como prejudicial ao seu tratamento, não tem sido de fácil resolução, pois o preconceito social à restrição de trabalho para o doente mental é muito mais cultural do que social, e nesta postura preconceituosa, a própria familia é também envolvida e colabora para fixar essa compreensão.

A familia põe a ociosidade como fonte de crise, relatando a não condição do seu doente para o trabalho e, ao mesmo tempo em determina o tipo de trabalho que ele deve desenvolver, com caracteristica bem peculiares. Isto está expresso nos discursos da familia.

\section{A OCIOSIDADE - FONTE DE CRISE}

A falta de atividade diária, de forma constante e rotineira, deixa o doente mental muito ocioso e não producente, podendo contribuir no desencadeamento de uma crise. Essa percepção da familia revela um fenômeno que pode ser preocupante, dentro das novas propostas de atendimento em saúde mental.

Revelando essa preocupação as familias situam-se nessa posição:

Agora não anda, só quando vem para cá, o resto é deitado. Ou dormindo ou deitado, não tem nada...Não há meio de dizer assim: vai passear, vai não. Home, vá passear, vá andar. Ou fica calado, ou diz assim: não fico por aqui mesmo...Ele é preguiçoso. O que não era. Só faz as coisas bem ligeiro e pronto. Só se sarrabulha por ali. (1a)

Quando ela não tá no hospital-dia, a gente nota que ela fica ansiosa...Dia de segundafeira, ela não sabe o que fazer, entendeu, fica parada... Ela quer encontrar uma coisa pra fazer e no entanto, não tem , né. Ela fica assim ansiosa...ela fica com aquela parte ociosa e acaba explodindo. (2b)

É só dormindo e fumando. (3a)

E aqui ele tanto dentro de casa é só deitado, fumando, fumando, fumando... quando não é deitado, fica sentado na calçada meio-dia em ponto, né.(3c)

Tem uma preguiça de lavar a roupa dela. Varrer esse terreiro que é muito grande, é raro, quando ela tá com uma disposição. (4a)

Ai em casa ele não quer fazer, não quer fazer...A única coisa que ele ainda faz é puxar água da cacimba pra encher o pote, e ainda é reclamando... do jeito que ele está ele não gosta é de fazer nada. Ele só quer tá em casa à vontade, só numa rede se balançando, aquela coisa toda, né, sem fazer nada...E no dia que ele tá em casa...é deitado numa rede e, ali passa a tarde. Eu digo muita coisa pra vê se ele faz alguma coisa... Vai se balançando, ele se levanta, vê a televisão... ele liga ali, não passa ali 10 minutos sentado, levanta e não quer nem saber, né. (6a)

A ociosidade, de acordo com as falas é ponto marcante e preocupante em muitas familias que têm usuários no sistema de hospital-dia.

Essa ausência de atividade e o estado adinâmico do seu doente não tem sido bem trabalhados pela familia, já que muitos são os conflitos existentes por conta de tal fenômeno.

Em alguns casos a adinamia do paciente é manifestação de um estado depressivo, como conseqüência do seu estado mórbido, que na maioria das vezes não é percebido pelos familiares, sendo a ele atribuido falta de coragem, ou mesmo não querer fazer alguma coisa, como se fosse algo que passasse pelo seu inteiro dominio.

Apreciar a sua produção após um trabalho desenvolvido é salutar para qualquer indivíduo, bem como traz sensações de ser capaz, de prazer, enfim de estar vivo. E estas sensações é 
que fazem com que o ser adquira forças e estimulo para prosseguir rumo a novos produtos, em busca de atingir um nivel de satisfação adequado.

Atividades consideradas pequenas também podem contribuir para que esse nivel de satisfação seja atingido. Em algumas atividades domésticas, o doente colabora da melhor forma possivel, transformando-a numa atividade significativa.

Ajuda a esposa dele, fralda essas coisas. ajuda aqui em casa, alguma coisa ele faz...Quando precisa ajudar ele ajuda, faz compras, tudo direitinho. (5a)

Ele resolve, me ajuda a resolver as coisas. Assim, as coisas de casa, combino com ele e tudo. (7a)

O envolvimento do familiar nas atividade domésticas, nas decisōes familiares, parece valorizar muito mais a presença dele naquele ambiente, como membro da familia, como forma de estimulá-lo a assumir responsabilidades, mostrando a ele que é capaz de realizá-las.

O grande periodo, correspondente a fase aguda da doença, quando o doente mental ficou sem assumir funçōes especificas, ou outras atividades, talvez tenha sido uma das coisas que contribuiram para o hábito do sedentarismo; como também a ociosidade reinante no hospital de tipo asilar e a indisponibilidade de voltar a trabalhar, imposta pelo preconceito social, comum à grande maioria dos doentes mentais.

Uma parte, porém, deseja firmemente arranjar um trabalho ao qual possa realmente se adaptar, sendo tão claro isso, que todos os da familia percebem essa necessidade de que o doente se sinta útil, numa sociedade que valoriza tanto o ser produtivo.

Ela acha que tem que ter dinheiro para comprar as coisas dela, esse negócio todo. (2a)

Ele fica assim preocupado, que quer trabalhar, né...Ele se sente muito chateado, viu. Ele disse: mãe a minha vida é muito ruim, esperar só que o papai me dê as coisas. (5b)

Nesse fenômeno, muita coisa tem a ser feita, no sentido de trabalhar com familia e participantes doentes, buscando, não somente uma ocupação para estes, mas, antes de tudo, torná-lo ser integrante e participe de um processo produtivo, capaz de construir as próprias possibilidade de vida, reinserindo-os ou mesmo inserindo-os na sociedade, tornando-os cidadăos.

\section{A NÃO CONDIÇÃO PARA O TRABALHO}

Desde que inicia seu processo de doença mental, o individuo é totalmente segregado da vida produtiva, passando a ser visto como um ser inapto para o trabalho, bem como incapaz de realizar qualquer açăo ou atividade.

A sociedade, de uma maneira geral, mesmo a própria familia, estabelece a incapacidade do doente mental de realizar qualquer atividade produtiva. Ao mesmo tempo logo que este dá resposta positiva ao tratamento, passa a ser cobrado da sua atuação como ser social.

Essa ambivalência de comportamentos sociais exterioriza não só o preconceito existente acerca da loucura, como também a superficialidade e estranheza com que a sociedade trata o individuo, quando este passa a não fazer parte do seu quadro de produção.

Eu acho que ele não tem condição de trabalhar. Primeiro eu vejo ele tão... parece que as mãos é assim dura, não sei como, fica pisando todo tempo. Ele vai trabalhar para quem? Quem é que quer? Ai a dificuldade que eu acho...Eu não entendo ele querer trabalhar. Ảs vezes lá na perícia, o médico diz: você quer trabalhar? Aí ele diz: quero, aí... ele fica todo tempo mexendo com os braços...Como é que pode? (1a)

Ela quer a todo custo trabalhar. Eu na minha opinião não acho que é o momento...Eu acho que lá não está preparada...Eu acho que poderia dar mais um tempo para ela não trabalhar agora. (2a) 
...Emprego para essas pessoas é muito dificil. (2b)

Bem, eu acho que ela doença dele, ele não tem mais capacidade de trabalhar, não. (3a)

Tem vontade de trabalhar, ele, mas, não tem condição, não, porque um dia ele está de um jeito, um dia ele está de outro...Porque eu penso que se ele for trabalhar é arriscado até dar um crise nele, como ele dava antigamente. Tá trabalhando...e ai dá uma crise, vai fazer uma crise com outra pessoa. Por isso eu digo, né. (3b)

.Ai foi na construção, não agüentou de novo. Ai eu disse: meu filho é melhor você parar. Espero que um dia Deus ajude que você se aposente, ai melhora as coisas pra nós. Não se preocupe não...que é que se pode fazer. Éo jeito, né...Agora ele não pode ter operação de nada. Ele fica, como se fosse um rapaz solteiro. Ele se preocupa com a filha que nasceu... Ele vai trabalhar, quando é com três, quatro dias năo agüenta, vem para casa, vive assim... (5b)

O problema que tem é de emprego. Mas isso a gente vai levando...falta emprego até para as pessoas que não tem... que não tem convivência com hospital. (5c)

Percebe-se, claramente, nesses depoimentos, o quanto a familia se posiciona contra o seu familiar que freqüenta o hospital-dia trabalhar, quando muitas vezes, ele próprio deseja ansiosamente possuir uma ocupação, ser útil.

Essa posição contrária ao trabalho do seu doente decorre do fato da familia percebê-lo ainda como ser incapaz de realizar suas atividades, bem como a dificuldade que este encontrará em arranjar um emprego adequado ao seu estado de higidez, porque emprego está difícil, inclusive para quem nunca teve distủrbios mentais.

Esta afirmação por parte das familias é um tanto carregada de preconceito, ao afirmar a incapacidade de o seu familiar realizar aiguma atividade, porém cobra deste a sua participação nos serviços domésticos ou a colaboração nas despesas familiares.

Essas duas idéias antagônicas dificultam uma relaçăo equilibrada, partindo do principio de que o próprio doente não consegue entender o que a sua familia deseja de si como comportamento aceitável, pois, ao mesmo tempo que o acha incapaz de trabalhar, cobra maior participação nas atividades da familia, de um modo geral.

Essa situação ambigua revela a necessidade que a familia tem também de um acompanhamento, para melhor experienciar suas situaçōes de conflito com o doente mental, colaborando com o seu tratamento de forma mais autêntica, sem tantos medos ou receios, mas, antes, convicta de que virão novas possibilidades para esse relacionamento entăo vivido.

Com base nessa percepção da familia, muito tem a ser feito pelos profissionais da área, que, decerto, será de grande valia para o processo de reforma psiquiátrica, centrando suas açōes mais na relação familiar.

\section{CARACTERISTICAS IDEAIS DE TRABALHO PARA O SEU FAMILIAR}

A caracteristica do trabalho a ser executado pelo doente é descrita pela familia, caso ele venha a desenvolver uma atividade fora de casa, pois o medo de desenvolver outra crise, que há tanto tempo não apresenta, aparece no discurso familiar vindo dai o estilo determinado de ocupaçăo a ser desenvolvida.

...A não ser que ele conseguisse assim um negócio que a pessoa realmente soubesse que ela tem problema. E que fosse trabalhar com uma coisa leve...Pra ajudá-la, pra que ela ficasse à vontade, pra que não exigisse tanto... Então sei lá, seria a familia ajudar. (2a)

Só se fosse um trabalhozinho, muito assim... muito levezinho, muito maneiro. porque eu acho que os nervo dele não resiste mais ele pegar um trabalho pesado e suado, fazer muita força não. Eu acho que ele não tem mais capacidade para isso, não. Um trabalhozinho leve, maneirozinho, que ele não se esforce muito, pode até fazer. (3a)

...Ele por exemplo não pode se agitar muito, porque ele fica nervoso, fica tremendo. $A$ não ser que seja uma coisa calma que é para ele fazer.(5c) 
A incapacidade do seu doente para realizar atividades comuns a todos os individuos é determinada pela familia, que especifica o tipo de trabalho que ele pode desempenhar sem trazer maiores problemas ao seu estado de saúde.

Essa percepção apenas corrobora o quadro de ociosidade, que tanto incomoda, revelado em outro momento nas suas descrições. Parece que a familia se encontra em um circulo de pensamentos e idéias que se contrapõem, não chegando a lugar ou posição definidos.

Essa indefinição gera insegurança no doente que deve ter por fonte de apoio a própria familia, que não está, a julgar pelas suas descrições, em condições de oferecer essa segurança necessária ao seu ser doente, dificultando todo o processo de adaptação a essa nova modalidade de tratamento que divide com a familia a assistência psiquiátrica.

A enfermagem, então, como participante dessa comunidade, tem um papel importante para definir, buscando, junto aos outros profissionais, possibilidades de solução para o trabalho com a familia, oferecendo a esta condições de enfrentar situações de conflito, inerentes a qualquer relação interpessoal, mas que, em situações especiais, são bem mais freqüentes.

$\mathrm{Na}$ interação, a subjetividade do ser deve manifestar-se a cada momento, como parte necessária desse processo, em que o respeito mútuo a essa manifestação deve ser preservado. E, para tanto, a familia deve ter suporte suficiente para modificar a antiga estrutura, fonte de crise, transmudando-a em uma nova maneira de viver conflitos e problemas de todas as ordens, no decurso dos dificilimos momentos do processo adaptativo.

\section{CONSIDERAÇÕES FINAIS}

Após realização desta pesquisa percebi que a familia está apta a empreender tentativas a procura de melhor qualidade de vida, tanto para o objeto da relação, quanto para seus sujeitos.

Nesse momento é que a enfermagem encontra espaço para agir, pois essa fragilidade desenhada nas falas quando do relato de experiências, se traduz em verdadeiro clamor solicitando auxilio. E esses reclamos só serão percebidos pela sensibilidade dos profissionais envolvidos no processo e prontificados a compreendê-los.

Em razão de estar a enfermagem comprometida com o cuidado, necessita ao trabalhar com familias, levar em consideração que esta no seu mister e consta de sua praxes a ação de cuidado, com base na visão de saúde, doença e cuidado. Para tanto a enfermagem precisa utilizar a sua percepção, tendo a habilidade de fazer a leitura das crenças, valores e práticas de que a familia se utiliza para realizar o cuidado. Então, essa percepção popular de cuidado deve ser considerada, pois a família, no seu mundo-vida vive momentos diferentes em cada fase da relação com o ser-doente. (Patrício, 1994).

Aproveitando o momento da familia está vivenciando esse novo momento, com o seu familiar mais presente, a enfermagem é obrigada a investir nesse campo da interação familia $x$ doente mental, contribuindo de forma significativa para o sucesso dessa experiência inovadora e que abrirá novas possibilidades para o atendimento psiquiátrico.

$\mathrm{Na}$ relação doente mental e trabalho, a familia descreve várias dificuldades, onde a ociosidade está presente, revelando a incapacidade do seu componente para o trabalho, ou indigitando-Ihe uma ocupação diferenciada adaptado a sua condição de doente, não percebendo o possivel estado depressivo que possa estar vivenciando, como manisfestação de sua patologia. 
Esse fenômeno, está acompanhado de preocupaçōes por parte da familia, que se apresenta, em alguns momentos molestada com o que poderá acontecer em decorrência desses fatos. Noutras oportunidades, acha-se incomodada, muitas vezes abominando as limitações que, de próprio arbitrio impõe ao seu membro mentalmente desordenado.

Não se pode afirmar que a familia é fonte do bem-estar ou da doença dos seus membros, pois a familia é o que fazemos dela. A doença mental, ordinariamente começa no interior do espaço familiar, e o relacionamento familiar é tanto fator patogênico como motor de cura. Portanto, não se pode negar que a familia e o seu espaço são mais causas do que vítimas de certos casos de doença mental. (Sonenreich,1992).

A violência como ação corrosiva da liberdade começa na familia do futuro doente mental. Praticamente ai a violência não tem fim, porquanto o doente sai dela para entrar no hospital psiquiátrico que, por sua vez, vai reproduzir as peculiaridades enlouquecedoras da familia do paciente, acrescendo-se o fator de que é no hospital que os funcionários passam a assumir os papéis desempenhados pelos componentes familiares. (Cooper,1989).

É de clareza meridiana que a relação familiar encontra-se abalada, isto denota a importância de se propor uma assistência mais voltada para a familia, onde o processo de alta de alguns sistemas de tratamento aberto, como é o caso do hospital-dia, precisa ser revisado e buscado novas alternativas para que isso aconteça sem trazer danos ao paciente e a familia e sem ter como conseqüência a internação psiquiátrica.

A ociosidade do paciente em casa é bem presente nos depoimentos, onde há relatos de que é essa situação contribui para o surgimento de uma nova crise.

Esse fenômeno desvelado se põe como um momento a ser refletido pelos profissionais de saúde, que, em algum momento de sua prática, podem estar contribuindo com esse pensar da familia na sua relação com a doença mental.

Nessa perspectiva, a enfermagem psiquiátrica precisa rever toda a sua prática e propor estratégias de mudanças visando, à construção de novo paradigma na assistência em saúde mental, pautado nas necessidades da familia que interage com o doente mental, para que 0 exercicio caótico e obsoleto ao entrar em metamorfose, possibilite novo caminhar rumo à cidadania do doente mental e aperfeiçoamento da civilidade defeituosa de sua familia.

\begin{abstract}
The relationship family $x$ mental ill, much more present in the psychiatric reform, constitutes a possibility to create new ways of understanding how the family percieves the relationship work $x$ mental ill. It is considered as a fundamental element in this research, the speech of the components of the family, due to their experience. In relationship mental ill $x$ work, the family describes several difficulties, where the idleness is present, revealing the inhability of his component for work, or apointting him a different occupation, adapted to his condition of sick, without percieving the possible depression felt as a consequence of his pathology.
\end{abstract}

KEYWORDS: work, mental ill, family.

RESUMEN: La relación familia x enfermo mental, mucho más presente en la reforma siquiátrica, constituye la posibilidad de crear nuevos caminos buscando comprender como la familia percibe la relación trabajo $\mathrm{x}$ enfermo mental. Es considerado como elemento fundamental en esta pesquisa, el discurso de los componentes de la familia del enfermo en razón de su experiencia vivida. En la relación enfermo mental y trabajo, la familia describe varias dificultades, donde el ocio está presente, revelando la incapacidad de ese componente para el trabajo, o señalándole una ocupación diferenciada, adaptada a su condición de enfermo, no percibiendo el posible estado depresivo que puede estar viviendo como manifestación de su patologia.

PALAVRAS LLAVE: trabajo, enfermo mental, familia. 


\section{REFERÊNCIAS BIBLIOGRÁFICAS}

BASSIT, Wiliam. A familia e a doença mental. In: D' INCAO,M. A.(Org.). Doença mental e sociedade: uma discussão interdisciplinar. Florianópolis: Graal, 1992.

BERENSTEIN, Isidoro. Familia e doença mental. Säo Paulo: Escuta, 1988

BRASIL. Projeto de lei $n^{\circ} 3.657$, setembro de 1989 . Dispõe sobre a extinção progressiva dos manicômios e sua substituição por outros recursos assistenciais e regulamenta a internação psiquiátrica compulsória. Brasilia, Câmara dos deputados, 1989.

CEARÁ. Lei no 12.151, julho de 1993. Dispöe sobre a extinção progressiva dos hospitais psiquiátricos e sua substituição por outros recursos assistenciais, regulamenta a internação psiquiátrica compulsória, e dả outras providências. Diário Oficial, Fortaleza, 12 de ago. de 1993.

COOPER, David. Psiquiatria e antipsiquiatria. 2. ed. São Paulo: Perspectiva, 1989.

COSTA, Jurandir Freire. Ordem médica e norma familiar. Rio de Janeiro: Graal, 1983.

ELSEN, Ingrid. Saúde familiar: a trajetória de um grupo. In Marcos para a prática de enfermagem com familias. Florianópolis: UFSC, 1994.

GARANHANI, Maria Lúcia. O significado da cirurgia para a criança. Ribeiräo Preto,1993. Dissertação(Mestrado em Enfermagem) - Escola de Enfermagem, Universidade de São Paulo, 1993.

MARTINS, Joel. ; BICUDO, M. A. V. A pesquisa qualitativa em psicologia: fundamentos e recursos básicos. 2. ed. São Paulo: Moraes, 1994.

PATRÍCIO, Zuleica Maria. O cuidar/cuidado com familia de adolescentes grávidas - aplicação de um marco conceitual de enfoque sócio-cultural. In: ELSEN, Ingrid et al. Marcos para a prática de enfermagem com familias. Florianópolis: UFSC, 1994.

PITTA, Ana Maria Fernandes : DALLARI, Gandolfi. A Cidadania dos doentes mentais no sistema de saúde do Brasil. Saúde em Debate, n. 36, p.19-23, out. 1992.

PRADO, Danda. O que é familia. Săo Paulo: Brasiliense, 1991.

RACAMIER, P.C. Perversão narcisica na familia do psicótico. In: VILHENA, Júnia de. Escutando a familia: uma abordagem psicanalitica. Rio de Janeiro: Relume-Dumará, 1991.

ROTELLI, Franco, LEONARDIS; Ota de, MAURI; Diana. Desisntitucionalização: uma outra via. In: NICÁCIO, Fernanda (Org.). Desinstitucionalização. São Paulo: Hucitec, 1990.

SOIFER, Raquel. Psicodinamismos de familia com crianças: terapia familiar com técnicas de jogo. Petrópolis: Vozes, 1982.

SONENREICH, Carol. A familia e o espaço psicológico. In: D' INCAO, M. A.(Org.). Doença mental e sociedade: uma discussão interdisciplinar. Rio de Janeiro: Graal. 1992.

SORDI, Rudyard Emerson. Reação da familia ao retorno de um de seus membros após uma primeira internação psiquiátrica: estudo de dez casos. In: ZIMMERMANN, David (Coor.). Temas de psiquiatria. Porto Alegre: Artes Médicas, 1980.

VASCONCELOS, Eduardo Mourão. Avaliação dos avanços recentes em legislação psiquiátrica no plano internacional: uma contribuiçăo ao debate sobre a reforma da lei psiquiátrica no Brasil. J. Bras. Psiq., v. 39, n. 5, p. 228-235, set./out. 1990.

VILHENA, Junia de. De uma solidão a outra: a palavra exilada. Uma história familiar. In: VILHENA, Júnia de. Escutando a familia: uma abordagem psicanalitica. Rio de Janeiro: Relume-Dumará, 1991. 